\title{
CLÃ VIRÁ: UM ESTUDO DE CUNHO ETNOGRÁFICO DA ESCRITA DE RESISTÊNCIA NO VALE DO SÃO FRANCISCO
}

\author{
Erika Jane Ribeiro ${ }^{1}$ \\ Cosme Batista dos Santos ${ }^{2}$ \\ Carla Conceição da Silva Paiva ${ }^{3}$
}

\section{Resumo}

Partindo de reflexões pontuais acerca da prevalência de um cânone literário patriarcal e da existência de práticas de letramento de maior prestígio social, este artigo busca apresentar eventos de letramento locais, informais, produzidos por mulheres no Vale do São Francisco, que reflitam as questões de gênero. Para tanto, as análises aqui apresentadas sustentam-se nas perspectivas sociais dos estudos do letramento defendidas por Kleiman (1995) e Brian Street (2006, 2014), bem como nas observações e análises feitas, por meio de um enfoque etnográfico, dos textos produzidos e apresentados pelo grupo Clã Virá, em Petrolina- PE e Juazeiro-BA.

Palavras-chave: Cânone literário. Gênero. Etnografia. Eventos de letramento.

\section{CLÁ VIR: A STUDY ETHNOGRAPHIC STUDY OF WRITING RESISTANCE IN THE VALLEY OF SAINT FRANCIS}

\begin{abstract}
Based on specific reflections on the prevalence of a patriarchal literary canon and the existence of more socially literate literacy practices, this article seeks to present informal, local literacy events produced by women in the São Francisco Valley that reflect the issues. of gender. Therefore, the analyzes presented here are based on the social perspectives of the literacy studies defended by Kleiman (1995) and Brian Street (2006, 2014), as well as on the observations and analyzes made, through an

\footnotetext{
${ }^{1}$ Mestranda em Educação, Cultura e Territórios Semiáridos - PPGESA. erikabrit@ hotmail.com

${ }^{2}$ Professor co-autor, pós-doutor em Ciência da Informação pela Faculdade de Letras da Universidade do Porto (FLUP) e Professor Pleno da Universidade do Estado da Bahia - UNEB. cbsantos@ uneb.br

${ }^{3}$ Professora orientadora, doutora em Multimeios pela Universidade Estadual de Campinas (UNICAMP) e Professora adjunta- UNEB. ccspaiva@gmail.com
} 
ethnographic approach, of the texts produced. and presented by the Clã Virá group, in Petrolina-PE and Juazeiro-BA.

Keywords: Literary canon. Genre. Ethnography. Literacy events.

\section{CLÃ VIRÁ: UN ESTUDIO DE TIPO ETNOGRÁFICO DE LA ESCRITA DE RESISTENCIA EN EL VALLE DEL SAN FRANCISCO.}

\section{Resumen}

A partir de reflexiones puntuales sobre la prevalencia de un canon literario patriarcal y de la existencia de prácticas de literacia de mayor prestigio social, este artículo busca presentar eventos de literacia locales, informales, producidos por mujeres en el Valle del San Francisco, que reflejen las cuestiones de género . Para ello, las discusiones aquí presentadas se sustentan en las concepciones de literacia que defendió Brian Street (2006, 20014) , así como en las observaciones y análisis realizados, por medio de un enfoque etnográfico, de los textos producidos y presentados por el grupo Clã Virá, en Petrolina- PE y Juazeiro-BA.

Palabras clave: Cánone literario. Género. Etnografía. Eventos de letras.

\section{Introdução}

A comprovada existência de um cânone literário masculino sempre figurou como um entrave à produção literária de mulheres, bem como à sua visibilidade, associando-se, desse modo, à ideia de um letramento dominante. Por muito tempo, a escrita feminina ficou limitada aos espaços domésticos e às temáticas mais intimistas e triviais. Rompendo com esse cenário excludente, mulheres vêm se organizando em coletivos, produzindo "eventos de letramento" que fomentam a escrita de resistência e a produção independente, em um múltiplo exercício de transgressão literária e social ao enfrentar as exclusões demarcadas pelas questões de gênero e, sobretudo, ao firmaremse, também, como indivíduos sociais independentes.

Há uma apropriação do feminino, ou melhor, do que deva ser o feminino, que define o papel que a mulher deve, supostamente desempenhar. Há, portanto, uma perda da identidade da mulher como indivíduo. Isto se dá nas mais diferentes culturas cuja divisão do trabalho entre os sexos faz com que os espaços para os homens sejam externos e para as mulheres, o universo domético. (EULEUTÉRIO, 2005, p.109) 
Por outro lado, as "práticas de letramento" literário sempre estiveram atreladas ao meio escolar e acadêmico e suas formalidades, como um modelo "autônomo" de letramento, em detrimento do modelo "ideológico" (STREET, 2014), de modo que todas as outras práticas realizadas em contextos informais ou não escolares tendem a ser desvalorizadas ou não consideradas. De igual modo, os letramentos locais são, constantemente, ocultados pelos letramentos dominates de maior prestígio social.

No Vale do São Francisco, um grupo de mulheres escritoras e atrizes escreve e apresenta seus textos em performances artísticas, sempre voltadas para a valorização do universo feminino e das suas próprias identidades. Em sua página no Facebook, elas se descrevem como "Clã tecido por mulheres em busca de si mesmas". O grupo Clã Virá foi inicialmente formado por cinco mulheres atrizes, que tiveram o teatro como fio condutor de sua formação e atuação, mas hoje conta com quatro participantes e mescla performance teatral e escrita literária numa perspectiva existencialista, de contato íntimo e livre com os elementos da natureza.

O grupo Clã Virá foi formado em novembro de 2015, por essas mulheres que carregavam afinidades teatrais e inquietações comuns acerca da arte, autoconhecimento e o Feminino Sagrado. Tudo partiu da comunhão de leituras, entre elas da obra "Mulheres que correm com lobos" da Clarissa Pinkola Éstés, que trata dos arquétipos de mulheres e das experiências de ser mulher, conta Ádila Madança, componente e idealizadora do grupo, enquanto fala sobre escrita de mulheres no Vale do São Francisco. De lá para cá, o grupo manteve os encontros e estudos, produzindo textos e montando performances onde a sua escrita flui, ocupa espaços e vai ao encontro do espectador, em locais e situações informais.

Entre elas, algumas escrevem textos literários, individualmente, porém todas participam do processo de criação e produção das performances, coletivamente. Em suas escritas, essas mulheres são movidas por leituras que elas consideram influenciadoras, bem como por discussões em torno das inquietações sobre ser mulher, num trânsito entre o Sagrado e o Social. Essas mulheres, conscientes do papel e força da mulher na sociedade, utilizam-se da linguagem teatral e da literatura como meio de expressão e sensibilização do público, sempre na perspectiva do autoconhecimento e de rompimento com os padrões patriarcais cerceadores. 
As performances, produzidas e apresentadas pelo Clã Virá, tomam como base textos literários escritos, individual ou coletivamente, pelas próprias mulheres componentes do grupo, de modo a dar visibilidade às suas vozes e experiências. Essas performances são apresentadas, quase sempre, em espaços informais, onde há uma grande circulação de pessoas, de modo que se privilegie uma interação mais holística entre os espectadores, o texto, o meio e as mulheres atuantes.

Diante do papel resistente do grupo frente ao cânone literário, notadamente patriarcal, e aos modelos hegemônicos e dominantes de letramento, o presente artigo analisa, a partir de um estudo de base etnográfica, textos literários produzidos pelas mulheres do Clã Virá e utilizados em suas performances, além de publicações feitas na página do grupo na rede social Facebook, buscando discutir de que modo essa escrita contribui para o rompimento dos estigmas em torno da escrita de mulheres e como elas se percebem, a partir da sua própria produção literária.

\title{
Práticas de letramento combativas e (re)construção das identidades das mulheres
}

A participação das mulheres na sociedade brasileira, por muito tempo, esteve condicionada à outorga masculina e na Literatura não foi diferente. A predominância de um cânone literário de base patriarcal ocultou e silenciou, durante séculos, vozes de mulheres escritoras, porém a postura resistente delas foi rompendo com os tradicionais padrões e construindo espaços de visibilidade, ainda insuficientes. Para Perrot (2008), a mudança na história das mulheres é uma questão de gênero, especificamente:

\begin{abstract}
A história das mulheres mudou. Em seus objetos, em seus pontos de vista. (...) Partiu de uma história das mulheres vítimas para chegar a uma história das mulheres ativas, nas múltiplas interações que provocam a mudança. Partiu de uma história das mulheres para tornarse mais especificamente uma história do gênero, que insiste nas relações entre os sexos e integra a masculinidade. Alargou suas perspectivas espaciais, religiosas, culturais (p. 16).
\end{abstract}

No que concerne à Literatura Brasileira, as assimetrias de gênero são percebidas ao passo que nos aprofundamos nesse universo e evidenciamos que poucas escritoras tiveram o merecido destaque nesse segmento, ficando relegadas, quase sempre, à condição de musas inspiradoras dos homens escritores ou de produtoras de uma 
literatura "menor", enfatizando as relações de poder que permeiam o meio literário. Muito por conta da existência forte do Cânone, o poder discursivo sobre as mulheres e suas criações era exclusivo dos homens, enquanto que a própria voz dessas mulheres era silenciada, restando o subjugo àquelas que irrompessem contra esse poderio.

Em compensação existe uma abundância, e mesmo um excesso, de discursos sobre as mulheres; avalanche de imagens, literárias ou plásticas, na maioria das vezes obra dos homens, mas ignora-se quase sempre o que as mulheres pensavam a respeito, como elas as viam ou sentiam (PERROT, 2008, p. 22).

É também nessa perspectiva de combate à contenção da voz e atuação das mulheres, sobretudo nos espaços literários que o Clã Virá apresenta uma escrita que questiona e se insurge contra os padrões patriarcais dominantes "De mulheres não se falava em um possível reconhecimento de liberdade por estarem calçadas, o homem e o livro nem falava de mulheres, quanto mais livres. As liberdades forjadas..." (CL ̃̃ VIRÁ, 2016).

Considerando-se esses atravessamentos, nota-se que as práticas de letramentos, produzidas no contexto escolar, também evidenciam as relações de poder e dominação de grupos considerados de maior prestígio, sobre outros marginalizados. Essas práticas impositivas e hegemônicas, determinadas por programas curriculares genéricos e descontextualizados, privilegiam o letramento "autônomo" (STREET, 2014) centrado na mecanização dos processos de escrita e leitura, que anula qualquer prática alternativa, de valorização da cultura e vivência dos envolvidos, num claro exercício de dominação.

Ainda tratando de práticas de letramento conectadas aos contextos, Street (2006) destaca que elas são constitutivas da identidade e da pessoalidade, por estarem associadas a padrões de comportamento e papéis sociais a serem exercidos. Partindo dessa fundamentação, esse autor estabelece uma relação entre os usos e significados dos conceitos de letramento e pessoa, alicerçados, sobretudo, no campo ideológico, ratificando que ambos estão, constitutivamente, relacionados, posto que as práticas de letramento são representativas das identidades dos sujeitos. Evidencia-se aqui, portanto, que aquisições de práticas de letramento, ligadas às identidades culturais, podem promover transformações que devem ser analisadas, especificamente, visto que formas 
culturais dominantes impõem seu letramento como único, fingindo neutralidade, enquanto marginalizam práticas alternativas.

(...) existe frequentemente uma relação fundamental entre os campos ideológicos de pessoalidade e letramento. $O$ que vem a ser uma pessoa, a ser moral e a ser humano, em contextos culturais específicos é muitas vezes representado pelo tipo de práticas de letramento em que a pessoa está comprometida, (STREET, 2006, p. 469).

Desse modo, considerando-se esse processo de construção da identidade e os padrões socialmente impostos aos sujeitos, nota-se que as práticas de letramentos dominantes, tanto no contexto escolar como fora dele, também reverberam as exclusões e estigmas em torno de grupos e espaços marginalizados, sendo, portanto, fortes disseminadores do patriarcado e das desigualdades de gênero, conceitos aqui entendidos a partir das concepções apresentadas por Saffioti (2015):

$\mathrm{O}$ exposto permite verificar que o gênero é aqui entendido como muito mais vasto que o patriarcado, na medida em que neste as relações são hierarquizadas entre seres socialmente desiguais, enquanto o gênero compreende também relações igualitárias. Desta forma, o patriarcado é um caso específico de relações de gênero. (SAFFIOTI, 2015, p. 126)

Ao tratar dos efeitos dos letramentos dominantes, Street (2014) cita o sudoeste asiático como exemplo e destaca que antes de sofrer o impacto ocidental, as práticas de letramento lá desempenhadas estavam, diretamente, conectadas aos costumes e práticas locais, sem ligação com instituições formais, e sua transmissão centrava-se na mulher (mãe). Após o domínio ocidental, esse letramento passa a ser institucionalizado e centrado na figura do homem, evidenciando-se a relação entre as práticas de letramentos dominantes e a imposição patriarcal.

É fundamental considerar os impactos culturais e sociais relacionados aos novos letramentos e os indivíduos neles envolvidos. Com esse propósito, Street (2014) apresenta vários outros estudos etnográficos importantes, que discutem a compreensão do letramento em termos mais vastos que os limites da escrita escolar, demonstrando vários usos e modos de apropriação dessa escrita, inclusive em distintas gerações, destacando, sempre, a existência de práticas silenciadas em nome de novas práticas dominantes. 
Tais ponderações suscitam discussões necessárias em torno dos processos de interculturalismo, por favorecerem à integralização de contextos e identidades diversas, de modo equânime, numa perspectiva plural de culturas que combata as hegemonias e colonizações, dentro e fora dos espaços escolares. Nesse sentido, ao analisar a educação escolar no contexto latino-americano, Candau \& Russo (2010, apud SANTIAGO, AKKARI E MARQUES, 2013 p.16) apontam um processo de hegemonização cultural, que consolidou uma cultura de base ocidental e eurocêntrica, como silenciador de vozes, saberes e culturas de determinados grupos estigmatizados e que, portanto, deve ser combatido.

\section{Teares metodológicos}

A fim de conhecer e compreender os elementos mais intrínsecos da escrita das mulheres do grupo Clã Virá, bem como analisar de que modo essas mulheres se percebem a partir dos eventos de letramento que produzem e como sua escrita literária contribui para a problematização e enfretamento das assimetrias de gênero, adotamos a pesquisa de cunho etnográfico por permitir uma observação mais aprofundada, que dá voz ativa ao grupo observado. Nesse sentido, Street (2014) destaca a necessidade de se "aplicar métodos etnográficos e as teorias sobre cultura aos diferentes letramentos atualmente praticados e vivenciados por pessoas de diferentes backgrounds sociais e culturais" (p.59).

A pesquisa de cunho etnográfico se justifica ainda mais, para esta análise, por permitir uma relação mais igualitária entre pesquisadora e as participantes do grupo, rompendo com os antigos paradigmas da pesquisa tradicional que categoriza o conhecimento e coloca o pesquisador sempre numa condição de superioridade. Tal escolha metodológica permite, ainda, a livre expressão das mulheres escritoras, tendo em vista a particularidade de suas produções, que refletem os seus ideais de liberdade e integração com o universo que as cerca.

Tendo em vista que o grupo não apresentou nenhuma nova performance durante o período em que se deu a pesquisa, a análise, foi feita com base nos textos e apresentações anteriores, disponibilizadas pelo grupo e publicados em rede social e, para tanto, valemo-nos de uma das variações da etnografia mais adequada às pesquisas que considerem as produções e os espaços virtuais, como as redes sociais, e o 
comportamento dos indivíduos na internet. Sobre a Netnografia, nos fala Gutierrez (2009):

Diferentemente da etnografia tradicional, a netnografia não exige a presença física do pesquisador. Assim, a abordagem inicial, a chegada ao campo de pesquisa, assume um formato diferente. (...) Além disso, nos espaços on-line, a mediação da tecnologia interpõe na interação entre pesquisador e pesquisados filtros relacionados às possibilidades e peculiaridades de cada tecnologia. (GUTIERREZ, 2009, p. 11)

Para a construção deste artigo, numa perspectiva mais holística, foram adotadas, também, a observação participante, a história de vida, seguidas da leitura e análise de textos escritos e apresentados pelo grupo, bem como da análise de fotografias e vídeos das apresentações, publicados na rede social do grupo. Esse percurso investigativo permitiu uma maior aproximação com a essência e a intencionalidade do grupo, desde a sua composição, o desenvolvimento da escrita dos textos, a seleção e a produção das performances, ressalvando a livre expressão das componentes do grupo. ${ }^{4}$

A associação da observação participante e história de vida reforçam o propósito dessa pesquisa que é compreender como essas mulheres escritoras se percebem, a partir da sua produção literária e de que modo essa escrita rompe com os padrões e estigmas alicerçados pelo cânone literário patriarcal, por meio de seus depoimentos, narrativas, análises de si mesmas e de seus escritos. A utilização da história de vida, como instrumento de pesquisa, justifica-se por permitir "um diálogo mais igualitário (...) através do qual a pessoa é incentivada a contar sua própria história de sua própria maneira e nos seus próprios termos, com um mínimo de interferência do pesquisador.”, como afirma Angrosino (2009, p. 23). Além desses instrumentos de pesquisa, utilizouse, também, a análise das postagens na rede social do grupo, a fim de ampliar as percepções e favorecer a uma compreensão mais densa do grupo em estudo.

A observação e conversa se deram entre os meses de maio e junho de 2018, mais precisamente com Ádila Madança que representou o grupo, por meio de recursos digitais e da participação em roda de conversa. As demais observações e análises foram feitas a partir das postagens na página oficial do grupo, numa perspectiva netnográfica.

\footnotetext{
${ }^{4}$ https://www.facebook.com/VIRACLADEMULHERES/ Acesso em: 30 abr. de 2018.
} 


\section{Tecendo análises}

O evento de letramento, unidade fundamental de estudo nesta pesquisa, é o evento social em que a escrita é parte essencial de uma determinada interação social, tanto em relação à própria interação entre os participantes, como em relação aos processos interpretativos implicados (KLEIMAN, 1995). Esse conceito de evento de letramento oferece aos investigadores e às investigadoras do letramento um modelo de análise para descrever quem, quando, onde, como e em que condições socioculturais as pessoas usam os textos escritos.

A rigor, neste trabalho, destacamos o papel interativo do letramento, nas relações sociais, seja de modo direto, por meio da oralidade ou através da escrita, inclusive à distância ou por meios virtuais, sem que haja a necessidade da presença física do autor e leitor. Tal característica enfatiza a multiplicidade e amplitude das práticas de letramentos, ultrapassando, inclusive, as fronteiras dos espaços formais, como a escola.

As práticas de letramento ideológico, particularmente as práticas não escolares, são, com efeito, importantes mecanismos de desconstrução das tradicionais relações de poder, alicerçadas, quase sempre, em práticas dominantes. Assim, a inserção das vivências e espaços locais, aliada à inclusão ativa, e não meramente figurativa, dos sujeitos envolvidos por meio de eventos de letramento resistentes e subversivos aos modelos autônomos (particularmente, nas práticas escolares), excludentes, podem produzir uma escrita socialmente engajada, capaz de romper com velhos paradigmas. E assim se apresenta a escrita das mulheres do Clã Virá.

Nesse sentido, a escrita do Clã Virá coloca-se como um importante instrumento de ruptura com as tradicionais bases hegemônicas do letramento - e do patriarcado-, no Vale do São Francisco, ao compartilharem em suas performances, escritos que questionam não só a determinação das identidades, mas também os modelos de comportamento e interação, alicerçados no poder patriarcal. Sua escrita apresenta-se como nítido exemplo dos letramentos alternativos, que resistem aos formatos préestabelecidos, tanto por incluírem necessárias discussões de gênero, como por ocuparem espaços não legitimados pelas práticas dominantes, alcançando públicos normalmente invisibilizados. 
Nessa perspectiva plural e interativa do letramento, além da observação dos eventos produzidos pelo grupo Clã Virá e a análise detalhada dos textos escritos que conduziram suas últimas apresentações performáticas, consideramos a maneira como as mulheres integrantes do grupo interagem entre si, por meio dos seus escritos, e de que modo essa interação se constrói com o público e com os espaços onde as performances são apresentadas. Dentre os vários "eventos de letramento" produzidos pelo grupo, discorreremos sobre os textos escritos e apresentados por meio das performances "Sobre Mulheres e Águas", realizado na Ilha do Fogo, entre as cidades de Juazeiro e Petrolina, em 2016; "Performance do Fogo", apresentada no Sarau Feminista, em 2016 e "Performance da Terra", também apresentada em 2016, às margens do Rio São Francisco.

Em sua página no Facebook, onde publicam textos, fotos e vídeos das performances, o texto de abertura já revela muito sobre a identidade do grupo, bem como sobre a inter-relação dessas mulheres, consigo mesmas e com a Natureza que as cerca.

Clã tecido por mulheres em busca de si mesmas. Caminham nas suas solidões, às vezes sós, às vezes juntas. Criam-se, destroem-se, recriam-se. Carregam em si belezas e feiuras próprias e da costura entre esses opostos, tecem-se. Tecem-se na escuta de suas próprias vozes, próprias danças, próprias poesias, próprios silêncios. Tecem-se na feitura dos próprios caminhos - às vezes claros, outras vezes obscuros.

Apressam-se pro tempo da demora e demoram-se. Do futuro sabem apenas que VIRÁ e que depois irá. Encontram a natureza de si mesmas na Natureza, mas não ignoram os concretos que as constituem. Estão em busca de si, estão em busca de ser. Nada são além da existência (CLÃ VIRÁ, 2016).

Há na escrita do Clã Virá uma fluidez que remete à dança; uma movimentação leve e metafísica, das palavras carregadas de múltiplos sentidos, que vão dizendo, espontaneamente, enquanto as ideias se entrelaçam ao ambiente, aos apetrechos de cena que carregam junto ao corpo, às vivências e sentimentos daquelas mulheres e do público leitor/espectador. No texto em análise, excepcionalmente, percebe-se a presença de um narrador, responsável por apresentar as mulheres do Clã Virá e seu processo criativo, referendado pelo uso de verbos na $3^{a}$ pessoa do plural - "caminham", "criam-se", “carregam" - entre outros, que, embora identifiquem os sujeitos aos quais se referem, não são capazes de retratá-los completamente. Nesse caso, específico, a escolha 
gramatical reflete um distanciamento intencional, a fim de criar um efeito de maior objetividade na descrição, diferentemente do que acontece nos demais textos criados e apresentados pelo grupo.

Preocupadas com questões universais e existencialistas, ligadas ao exercício livre da feminilidade, desconectadas dos padrões impostos socialmente, as mulheres do Clã Virá acabam por estabelecer relações, também, com os elementos locais ao utilizarem uma linguagem coloquial e, sobretudo, por valerem-se, intencionalmente, de espaços locais ainda não - ou pouco - utilizados para as práticas culturais como as margens e águas do Rio São Francisco e o ponto de embarque das barquinhas que fazem a travessia Juazeiro-Petrolina.

Fotografia 1: Performance "Sobre Mulheres e Águas- Ilha do Fogo - 2016"

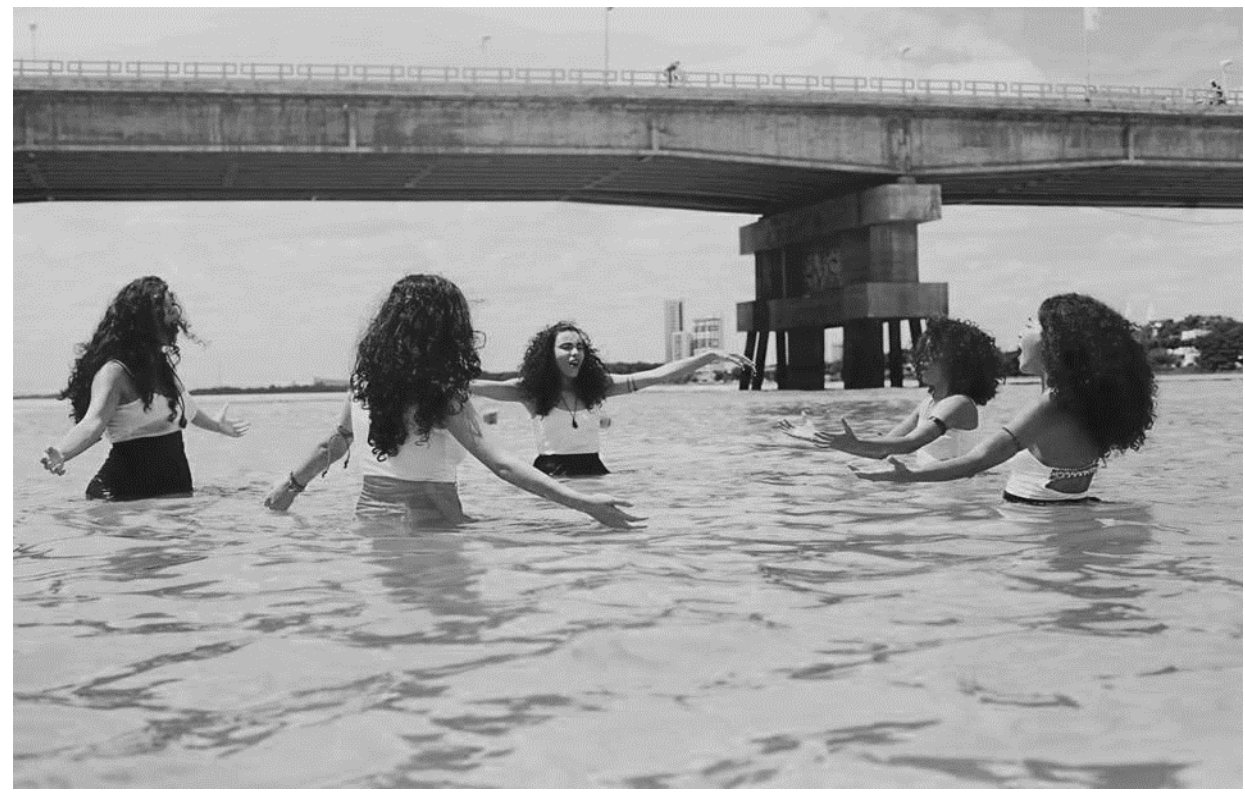

Fonte: Lizandra Martins ${ }^{5}$

Visando o rompimento com os padrões canônicos patriarcais e com o paradigma dominante da literatura, essas mulheres propõem a construção de um tipo de escrita bem diferenciado, caracterizado, principalmente, pela sua dupla intencionalidade - a escrita e a performance em espaços não convencionais de arte, como as ruas, águas e margens do rio, entre outros. Esse tipo de produção literária parte da ideia de que não se deve ter um local formal e "adequado" para acontecer uma performance literária, essas mulheres

\footnotetext{
${ }^{5}$ Disponível em: https://www.facebook.com/VIRACLADEMULHERES/ Acesso em: 30 abr. de 2018.
} 
estão não só subvertendo os modelos dominantes e colonizadores de escrita, mas também gerando uma interculturalidade extremamente significativa, pois permitem o acesso cultural também a um público não-letrado, relegado, como banhistas, transeuntes, vendedores ambulantes, etc. Além disso, as performances literárias conectam questões socioculturais globais, como as assimetrias de gênero, aos elementos da natureza local: as fogueiras na Ilha do Fogo e as águas do Velho Chico, por exemplo.

A produção do Clã Virá comunica-se com as forças ancestrais da Terra, do Fogo, das Águas e delas vai tecendo novas e dialógicas teias, onde a força e resistência da mulher, ao longo dos tempos, são alimentadas pelo poder da palavra. Na fotografia 1 , evidencia-se a ruptura com a espacialidade tradicional e uma interconexão, propiciada pela performance "Mulheres sobre águas", ao intercruzar as forças do feminino e das águas. Durante a roda de conversa, Ádila Madança, ao falar sobre o grupo e suas produções, vai movimentando as mãos numa harmonia dançante, enquanto tece um retrospecto do grupo. Toda a sua narrativa é permeada de poesia e sorrisos e enquanto conta sobre a formação e propósitos do grupo, recita um dos poemas mais emblemáticos que compõe a "Performance do Fogo", a seguir. Nesse poema há um grito de denúncia e resistência às imposições estabelecidas pelo patriarcado, demonstrado pelo uso da primeira pessoa, evidenciando um eu- poemático feminino, além das referências diretas à perseguição que as mulheres sofreram durante a inquisição, bem como o processo de enfrentamento e reconstrução dessa identidade feminina:

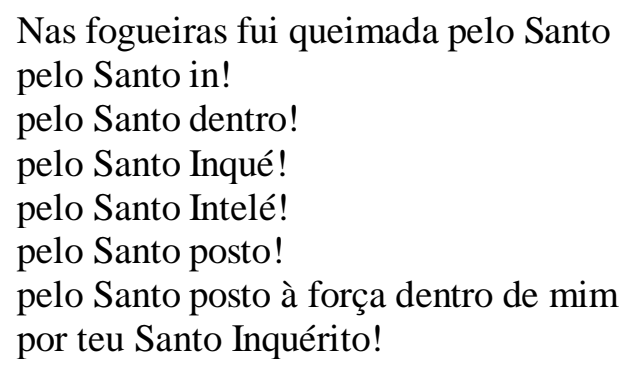

Mas eu, que sou filha da Santa cheia de Mácula, que abarco o profano e o sagrado, eu ri. Ri nas fogueiras porque os Santos se achavam donos de mim.

E nas mesmas fogueiras em que fui queimada, eu renasci. Em meu suposto fim, o vento me propagava para lugares onde antes eu não alcançava ir. Minha cinza se dispersava e eu ressemeava pelo mundo as outras formas de mim. (CLÃ VIRÁ, 2016a). 
O texto produzido e apresentado na "Performance do Fogo" (Fotografia 2) traz referência direta à Inquisição, também conhecida como Santo Ofício e a todos os julgamentos e condenações dela advindos, inclusive a morte na fogueira, sendo as mulheres alvos constantes dos inquisidores. A partir de elementos lexicais derivados da ideia geral de inquisição, bem como da referência por meio da reiteração "pelo Santo", o eu-poemático feminino ressalta a opressão dos sistemas e as barreiras que lhes foram impostas, para ao final destacar sua libertação por meio do recurso metafórico "fogo".

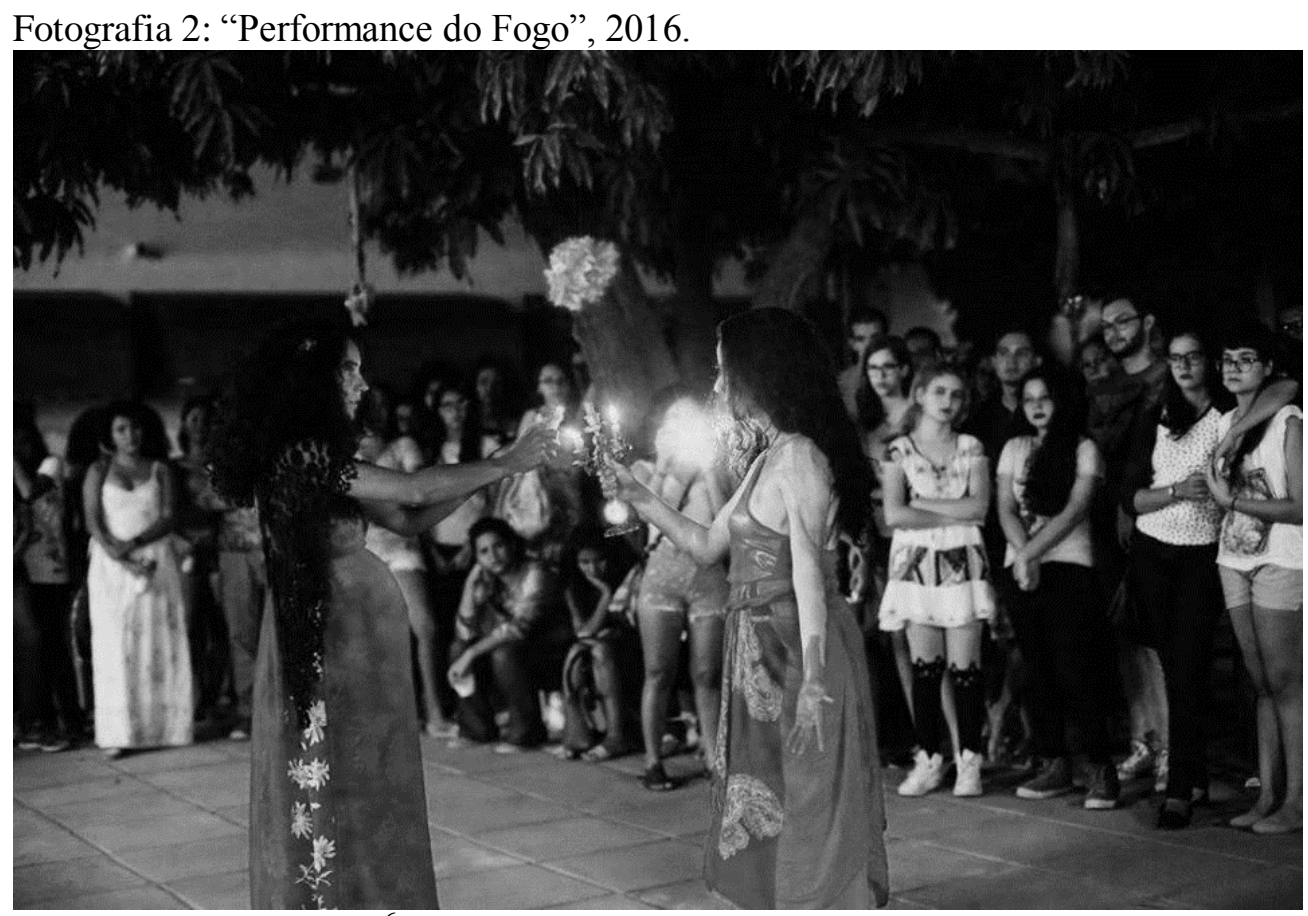

Fonte: Lizandra Martins ${ }^{6}$

Assim, a fotografia 2 retrata o modo visceral e libertário - perceptível no gestual, nos apetrechos de cena, sobretudo na representação do fogo, e em suas vestes reluzentes - como os textos produzidos pelas mulheres do Clã Virá são vivenciados compartilhados com o público, que também passa a ser parte da construção performática tecida a partir do texto, numa perspectiva de "estado de presença" dessas mulheres, de estarem atentas ao que acontece em volta, como esclarece Ádila Madança, ao narrar sobre as performances construídas e apresentadas pelo grupo:

A performance requer para si esse estado de presença que é diferente de um espetáculo (...) como a gente está lidando com várias situações

\footnotetext{
${ }^{6}$ Disponível em: https://www.facebook.com/VIRACLADEMULHERES/ Acesso em: 30 abr. de 2018.
} 
de espaço, de espacialidades...a gente tem que se relacionar com vários elementos, com o público, com os espaços, com os elementos que a gente tá carregando no corpo da gente, com as nossas sensações, nossas próprias emoções... ${ }^{7}(2018)$.

Desse modo, a escrita literária das mulheres do Clã Virá tem estabelecido interações com o público, ao passo que problematiza o lugar de fala das mulheres, colocando-as como agentes diretas na propagação de suas vozes. Com isso, essa escrita acaba por questionar as possíveis acepções de liberdade, a partir das desigualdades de gênero e dos silenciamentos e ocultações delas originadas, como demonstra o trecho a seguir, apresentado na "Performance da Terra": "Um homem, através de um livro, um dia me disse da liberdade e de sapatos. Só se reconhecia um homem livre moderno por seus pés cobertos de seja lá qual material fosse - distinto e equivalente ao seu trabalho e status." (CLÃ VIRÁ, 2016b)

As mulheres do Clã Virá escrevem sobre e para além das suas vivências. Arrematam os fios dos seus sentidos, dão-lhes sustança na fusão com os sentimentos e as experiências de interações, emaranham-se às energias dos espaços inusitados e vão tecendo novas formas de (re)pensar as identidades e os papéis sociais das mulheres, acreditando no devir, prontas para o que Virá.

\section{Percepções finais para novos alinhavos}

Com aporte nos estudos de letramentos apresentados por Brian Street (2006), a partir de suas experiências etnográficas em contextos socioculturais variados, constatamos a existência de múltiplas práticas de letramentos e a necessidade de considerarmos essa pluralidade, respeitando os saberes e vivências de grupos marginalizados, de modo a garantir usos interculturais e sociais da escrita, dentro e fora dos espaços escolares.

A análise dos textos produzidos pelo Clã Virá, em conjunto com as demais observações demonstraram que, além do rompimento com os estigmas, construídos e alimentados por muito tempo, a escrita dessas mulheres permite processos mais aprofundados de autoconhecimento e de inter-relação, a partir da problematização das assimetrias de gênero, por meio de processos artísticos.

\footnotetext{
${ }^{7}$ Trecho extraído da fala de Ádila Madança, enquanto narra sobre a composição e apresentação das performances do grupo, durante uma roda de conversa sobre a produção literária de mulheres, no Vale do São Francisco, em 18/06/18, organizada pela pesquisadora Erika Jane Ribeiro.
} 
Ao organizarem-se em grupos, essas mulheres escritoras fortalecem suas vozes e, juntas, vão rompendo com as limitações e silenciamentos, garantindo maior acessibilidade às suas produções literárias, visto que recorrem a outros suportes de divulgação, distintos dos livros, a exemplo das apresentações de performances. Ao mesclarem elementos literários e performáticos, as mulheres do Clã Virá conseguem acessar públicos variados em múltiplos contextos, ecoando essa voz de mulher que resiste através da palavra que dança e tem cor. Por meio dessas práticas diferenciadas de letramentos literários essas mulheres vão conquistando espaços sociais, ao passo em que acessam e instigam outras mulheres à ação.

É por meio da escrita que essas mulheres reexistem, compreendendo a importância dos seus papéis sociais, desempenhados livremente e ampliando suas vozes e inquietações diante das desigualdades de gênero e, sobretudo, inter-relacionando essa escrita com as diversas vivências, espacialidades e sujeitos, num processo intercultural e plural. É uma escrita que transita fluída entre a universalidade das temáticas e representações e as singularidades das mulheres e homens do Vale do São Francisco, sempre tecendo novas vozes em nome da liberdade de ser mulher.

\section{Referências bibliográficas}

ANGROSINO, Michael. Etnografia e observação participante. Porto Alegre: Artmed, 2009.

CANDAU, Vera Maria Ferrão; RUSSO, Kelly. Interculturalidade e Educação na América Latina: uma construção plural, original e complexa. Revista Diálogo Educacional., Curitiba, v. 10, n. 29, p. 151-169, jan./abr. 2010.

CLÃ VIRÁ. Mimeo. Material divulgado na Performance do Fogo. Juazeiro, 2016a. Mimeo. Material divulgado na Performance da Terra, Juazeiro, 2016b.

ELEUTÉRIO, Maria de Lourdes. Vidas de Romance: as mulheres e o exercício de ler e escrever no entresséculos 1890 - 1930. Rio de Janeiro: Topbooks, 2005.

GUTIERREZ, S. A etnografia virtual na pesquisa de abordagem dialética em redes sociais on-line. Rio de Janeiro: 32a Reunião Anual da Anped, 2009. Disponível em: http://32reuniao.anped.org.br/arquivos/trabalhos/GT16-5768--Int.pdf. Acesso em: 08 Jun. 2018.

KLEIMAN, Ângela B. (Org). Os significados do letramento: uma nova perspectiva sobre a prática social da escrita. Campinas (SP), Mercado de Letras, 1995. 
LÓPEZ, Graciela Lima. O método etnográfico como um paradigma científico e sua aplicação na pesquisa. Textura, Canoas, V. 1, n.2º sem, p. 45-50, 1999. Disponível em: www.periodicos.ulbra.br/index.php/txra/article/download/660/470. Acesso em: 01 Jun. 2018 .

PERROT, Michelle. Minha história das mulheres Tradução Angela M. S. Côrrea. São Paulo: Contexto, 2008.

SAFFIOTI, Heleieth I. B. Gênero, patriarcado, violência. 2. ed. São Paulo: Editora Fundação Perseu Abramo, 2015.

SANTIAGO, Mylene Cristina; AKKARI, Abdeljalil; MARQUES, Luciana Pacheco. Os caminhos do interculturalismo no Brasil. In:.Educação intercultural: desafios e possibilidades. Petrópolis: Vozes, 2013. p. 15-33.

SOARES, Magda. Novas práticas de leitura e escrita: letramento na Cibercultura. Educ. Soc., Campinas, vol. 23, n. 81, p. 143-160, dez. 2002. Disponível em http://www.cedes.unicamp.br. Acesso em: 20 Mar. 2018.

STREET, Brian. Letramentos sociais: abordagens críticas do letramento no desenvolvimento, na etnografia e na educação. Letramento e mudança social: a importância do contexto social no desenvolvimento de programas de letramento. Trad. Marcos Bagno. São Paulo: Parábola, 2014.

Perspectivas Interculturais sobre o Letramento. Trad. Marcos Bagno. Revista Filologia e Linguística Portuguesa, São Paulo, n. 8, p. 465-488, 2006. Disponível em: https://www.revistas.usp.br/flp/article/view/59767 . Acesso em: 02 Mai. 2018. 